\title{
The Effects of Rainfall Intensities and Duration on SCS-CN Model Parameters under Simulated Rainfall
}

\author{
Xiaoxian Wang ${ }^{1}$ and Huaxing $\mathrm{Bi}^{1,2,3,4,5,6, *(\mathbb{D})}$ \\ 1 College of Soil and Water Conservation, Beijing Forestry University, Beijing 100083, China; \\ wxx2005@bjfu.edu.cn \\ 2 Forest Ecosystem Studies, National Observation and Research Station, Jixian 042200, China \\ 3 Key Laboratory of State Forestry Administration on Soil and Water Conservation, \\ Beijing Forestry University, Beijing 100083, China \\ 4 Beijing Soil and Water Conservation Engineering Technology Research Center, Beijing Forestry University, \\ Beijing 100083, China \\ 5 Forestry Ecological Engineering Ministry of Education Engineering Research Center, \\ Beijing Forestry University, Beijing 100083, China \\ 6 Beijing Collaborative Innovation Center for Eco-Environmental Improvement with Forestry and Fruit Trees, \\ Beijing 102206, China \\ * Correspondence: bhx@bjfu.edu.cn; Tel.: +86-10-6233-6756
}

Received: 28 April 2020; Accepted: 1 June 2020; Published: 4 June 2020

check for updates

\begin{abstract}
The Soil Conservation Service curve number (SCS-CN) method has been widely used in rainfall-runoff modelling; however, the direct effects of rainfall intensities and duration, which are major factors in hydrological engineering design, on its parameters (initial abstraction ratio $(\lambda)$ and potential maximum storage (S), the latter is transformed into curve number $(C N)$ ) have seldom been studied. In this study, we chose simulated rainfall experiments on runoff plots $(30 \mathrm{~mm} / \mathrm{h}$, $180 \mathrm{~min} ; 60 \mathrm{~mm} / \mathrm{h}, 90 \mathrm{~min} ; 90 \mathrm{~mm} / \mathrm{h}, 60 \mathrm{~min}$ ) to obtain synchronized rainfall-runoff data and calculated the parameters using general model fitting and event analysis methods every ten minutes throughout the duration. The results indicate that the parameters changed with rainfall intensities and duration. $S$ decreased as the rainfall intensities increased. Under the same rainfall intensity, the $S$ increased with the duration overall. The corresponding $\lambda$ changed with rainfall intensities and duration, and has no obvious relationship under different rainfall intensities. Initial abstraction in the event analysis method is the same as the actual situation and we chose these parameters obtained with the event analysis method as our selected parameters. These selected parameters and the parameters obtained using Fu et al.'s method which was based on the standardized procedure in NEH-630 were evaluated by the Nash-Sutcliffe efficiency (NSE), the percentage deviation coefficient (PBIAS), and the ratio of the root mean square error to the standard deviation of measured data (RSR). The results show that the statistics for the selected parameters satisfied the evaluating standard, and have a better value, while the statistics for the parameters obtained by Fu et al.'s method declined as the rainfall intensity increased, and PBAIS was out of the standard range under $90 \mathrm{~mm} / \mathrm{h}$ rainfall intensity condition. This indicates that the rainfall intensities and duration have important effects on the parameters of the model, and the parameters vary dynamically with the rainfall intensity and duration. These results could be useful for hydrological design in which engineers consider the return period (i.e., rainfall intensities and duration).
\end{abstract}

Keywords: rain simulator; Natural Resource Conservation Service Curve Number model (NRCS-CN); rainfall intensity and duration 


\section{Introduction}

Rainfall-runoff simulation is the basis of hydrological and soil erosion models. Scholars usually calculate runoff using infiltration models, such as Philip, Green-Ampt and Horton, but these model's parameters are difficult to obtain [1], and they have several parameters, which easily leads to the problem of overparameterization [2]. The U.S. Department of Agriculture created the Soil Conservation Service curve number (SCS-CN) (nowadays Natural Resource Conservation Service Curve Number (NRCS-CN)) model based on rainfall events in the 1950s. The model only contains two parameters: the initial abstraction ratio $(\lambda)$ and the curve number $(C N)$. The $C N$ comprehensively reflects the influences of environmental factors on the runoff, such as soil type, soil moisture, land use and vegetation cover [3]. Because the model is simple in structure, and can effectively predict the runoff, it has been applied to areas where there are no rainfall-runoff data. It has been promoted in many countries and regions, such as the United States, India, China, and the Mediterranean [4-8].

In order to apply the model accurately and reasonably, the studies of the determination of its parameters under the influence factors (different region, land use), comparison to other models and improving the model structure have been carried out. How to determine the model's parameters reasonably is especially important for the application of the model, for $C N$ is a sensitive parameter and has a great influence on the runoff volume prediction. Fu et al. [6] studied the value of $C N$ in Beijing, while Li et al. [9] studied the main influencing factors of potential maximum storage $(S)$ in the loess area of China. Zhou et al. [8] studied the initial abstraction ratio in the loess area of China. Scholars also have done a lot of research on the differences between SCS-CN and other models. Rawls [10] compared the difference between this model and Green-Ampt model and found that the accuracy of Green-Ampt was higher. Fu et al. [1] compared the different runoff calculation methods in the Beijing area and drew the same conclusion. In order to improve the accuracy of this model, some changes and new parameters were put forward or combined into the model. Huang [11] derived the relationship between slope and $C N$ value, while Chen et al. [5] applied this relationship in hillslope cropland of purple soil. Jiao et al. and Rajib et al. [12,13] combined the soil evapotranspiration and moisture model into the original runoff model, and the prediction accuracy was improved. Mishra and Singh [14-16] proposed an improved Mishra-Singh (MS) model by adding the pre-humidity to the model, Sahu improved MS to the Sahu-Mishra-Eldho (SME) model, and then added rainfall duration, and put forward the modified Sahu-Mishra-Eldho (MSME) model. All the above studies promoted the understanding and application of the model. However, the influence of rainfall intensities and duration on the parameters of the model has not been considered comprehensively in the existing studies.

In the beginning, rainfall was used as the basis of calculation, and the influence of rainfall intensities and duration was not taken into account [17]. The parameters of the model provided in the National Engineering Manual, Hydrology Section 630 (NEH-630) is the median logarithmic frequencies derived from the annual maximum rainfall runoff. For all return periods, the $C N$ is taken to be same. Previous studies have shown that rainfall intensities and duration have an important impact on runoff production processes such as vegetation interception [18], infiltration process [19], etc., and will inevitably have an impact on the corresponding parameters in the model, such as initial abstraction ( $I a)$, infiltration $(F)$, etc., and then may affect the parameters of the model. Rawls [10] and Fu et al. [1] found that the Green-Ampt model had higher accuracy and the main reason was the SCS model did not take into account the influence of rainfall process on runoff generation. Sahu [15] proposed the MSME model which combines the rainfall duration into the SCS, and the prediction efficiency of the model was improved. Although the study improved the accuracy, more parameters were added and the hypothesis that the runoff production factors follow the same hypothesis as the whole rainfall in the rainfall process had not been strictly proved, and the influence of rain intensities was not taken into account in the hypothesis.

Rainfall intensities and duration are important hydrological factors which are inversely correlated with each other in a certain return period. The characteristics of rainfall are different in different 
geographical areas, and there are many types of rainfall, even in the same area. Urban drainage and stormwater management systems are designed according to different return periods. Figure 1 shows the relationship between rainfall intensities and duration under different return periods according to the recommended rainfall formula in the Local standard of Beijing municipality: Code for the design of stormwater management and harvest engineering [20]. It can be seen that rain intensity changes with the duration at every return period, the shorter the duration, the greater the rainfall intensity. In order to improve the simulation accuracy of the hydrological model based on the SCS-CN model and to provide the scientific basis for the planning and design of flood control, it is necessary to study the influences of rainfall intensities and duration on the parameters of the model.

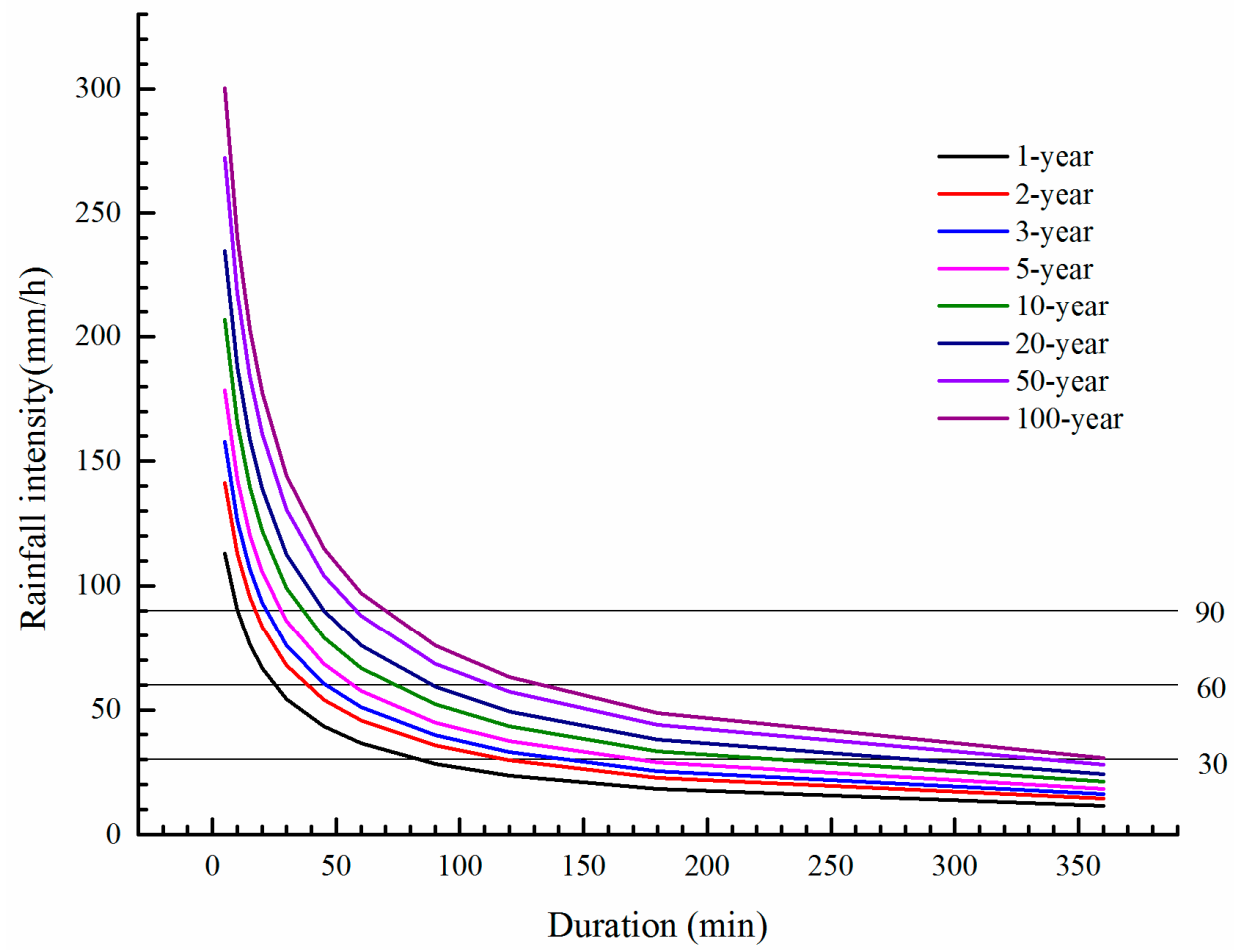

Figure 1. The relationship between rainfall intensity and duration in Beijing area.

Therefore, in order to study the effects of different rainfall intensities and duration on the model parameters (S/CN and $\lambda$ ), we carried out simulated rainfall experiments on simulated sloped runoff plots and obtain synchronized records of rainfall and runoff under three types of rainfall intensity and duration. We calculated $S$ and $\lambda$ every ten minutes by the general model fitting and event analysis methods using rainfall and runoff synchronized data. The parameter calculated and the parameters obtained using Fu et al.'s method were evaluated using three statistics (the Nash-Sutcliffe efficiency (NSE), the percentage deviation coefficient (PBIAS) and the ratio of the root mean square error to the standard deviation of measured data (RSR)). In the end, we give a discussion on the effects of rainfall intensities and duration on the model parameter values.

\section{Model}

The SCS-CN is based on two hypotheses and the principle of water balance. The first hypothesis is:

$$
\frac{F}{S}=\frac{Q}{P-I a}
$$

where $F$ is the infiltration $(\mathrm{mm}) ; S$ is the potential maximum retention $(\mathrm{mm}) ; Q$ is the surface runoff $(\mathrm{mm}) ; P$ is total rainfall $(\mathrm{mm})$; and $I a$ is the initial abstraction $(\mathrm{mm})$. 
The second hypothesis is:

$$
I_{a}=\lambda S
$$

where $\lambda$ is the initial abstraction ratio.

The principle of water balance is:

$$
P=I a+F+Q
$$

Putting Equation (3) into Equation (1), $Q$ can be obtained as:

$$
Q=\frac{(P-I a)^{2}}{P-I a+S}
$$

Putting Equation (2) into Equation (4), then $Q$ can be obtained as:

$$
Q=\frac{(P-\lambda S)^{2}}{P+(1-\lambda) S}
$$

$S$ is transformed into $C N$ through:

$$
C N=\frac{1000}{10+\frac{S}{25.4}}
$$

\section{Materials and Methods}

\subsection{Simulated Rainfall System}

This study was carried out in Beijing Forestry University simulated rainfall hall, located in Jiufeng National Forest Park. The simulated rainfall system specially developed for scientific research experiments was made by Xian Qingyuan Co. (Xi'an, China). The simulated rainfall system is not restricted by nature, and the rainfall and duration can be adjusted. Several investigators [21,22] have conducted various runoff and erosion experiments using this system. This system includes three parts: a rainfall system, control system and water supply system. The rainfall process can be automatically or manually controlled. The nozzle of the artificial rainfall system is a rotary down spraying nozzle developed by Spraying Systems Co. (Glendale Heights, IL, USA). The superimposed nozzle method is used to simulate natural rainfall. The rainfall uniformity is above $85 \%$. The nozzle height is $12 \mathrm{~m}$, so the raindrop can reach terminal velocity. This system is equipped with a highly sensitive rain gauge, so the rainfall intensity can be measured in real time and precisely controlled.

\subsection{Runoff Plots}

The runoff plots were formed through placing soil into steel tanks. The tank's dimensions were $2 \times 0.5 \times 0.3 \mathrm{~m}$. There were two runoff plots, one for calibration, the other for validation. The plot slope can be adjusted through a gradient adjustment device under the steel tank. In this study, we set the slope to 10 degree. A collecting bucket was installed at the lower terminal to collect the runoff.

The soil was taken from farmland in Changping, Beijing, which is cinnamon soil, one of the typical soils in this area. The soil bulk density was $1.31 \mathrm{~g} / \mathrm{cm}^{3}$ with an organic content of $1.5 \%$. The distribution of the soil particles is shown in Table 1. The soil type belongs to B in NEH-630. The soil was sieved through a $10 \mathrm{~mm}$ soil sieve. The tank was filled with the soil evenly layer by layer with soil bulk density controlled at $1.31 \mathrm{~g} / \mathrm{cm}^{3}$. The soil moisture content was controlled at $28 \%$ before the experiment. 
Table 1. The distribution of the soil particles.

\begin{tabular}{|c|c|c|c|c|}
\hline \multirow{2}{*}{ Soil Texture } & \multicolumn{3}{|c|}{ Soil Particles/(\%) } & \multirow{2}{*}{ Porosity/(\%) } \\
\hline & $2-0.02 \mathrm{~mm}$ & $0.02-0.002 \mathrm{~mm}$ & $<0.002 \mathrm{~mm}$ & \\
\hline Silt loam & 29 & 71 & 0 & 49.6 \\
\hline
\end{tabular}

The main experimental factors are shown in Table 2. The type of land use was pasture, and the vegetation used in our experiment was Festucaelata which is typical in North China. The vegetation coverage was about $60 \%$. The planting method was transplantation, with the planting row vertical to the plot slope. Grass purchased was planted with a row width $30 \mathrm{~cm}$ and a row spacing $20 \mathrm{~cm}$. After planted, the grass was cured until it grew new roots and fully resumed.

Table 2. The main experimental factors.

\begin{tabular}{ccccc}
\hline Serial No. & Antecedent Moisture Condition & $\begin{array}{c}\text { Cover Degree } \\
\mathbf{\%}\end{array}$ & $\begin{array}{c}\text { Rainfall Intensity } \\
\mathbf{m m} \cdot \mathbf{h}^{\mathbf{- 1}}\end{array}$ & Duration/min \\
\hline 1 & AMCI & 60 & 30 & 180 \\
2 & AMCI & 60 & 60 & 90 \\
3 & AMCI & 60 & 90 & 60 \\
\hline
\end{tabular}

The experiments were carried out from June to August, the experiment time interval was 7-8 days. The antecedent moisture condition (AMC) is divided into three conditions (AMCI, AMCII and AMCIII). According to the results of research by Fu et al. [6] on $\mathrm{CN}$ values in the Beijing area, this experimental condition was assigned to AMCI.

\subsection{Experiments and Data Collection}

Through the rainfall intensity-duration-frequency diagram of Beijing (Figure 1), we chose 30, 60, $90 \mathrm{~mm} / \mathrm{h}$ intensities as experiment rainfall intensities. The total rainfall was $90 \mathrm{~mm}$, and the rainfall type was uniform. A total of 3 replicates were performed for each intensity of rainfall.

Before the experiment, a bucket was placed under the collecting tank to receive the runoff. The start of the simulated rainfall was recorded as the beginning time of the rainfall, and the time when the runoff begins was recorded as the runoff beginning time. After the runoff beginning, the bucket that had been placed under the collecting tank was substituted with an empty bucket constantly. Within the first $20 \mathrm{~min}$, the substituting interval was $2 \mathrm{~min} ; 20 \mathrm{~min}$ later, the interval was changed to $5 \mathrm{~min}$; after $1 \mathrm{~h}$, the interval was changed to $10 \mathrm{~min}$. After each replacement, the replaced bucket was placed in the idle position at the rainfall hall in the order of substitute. After the rainfall was over, runoff in the buckets was measured and recorded.

\subsection{Runoff Intensity and Runoff Volume Caculating Method}

Through Section 3.3, we obtained the synchronized break-point data of runoff. The runoff amount was obtained by adding up the collected runoff. The runoff depth was equal to runoff amount divided by runoff area. The runoff intensity was the runoff depth every minute, calculated by dividing the runoff depth versus the time the runoff was used.

\subsection{Calculation Methods of the Mode's Parameters}

The calculation methods used in this study for the parameters were the general model fitting method and the event analysis method. These methods are the same as used by Woodward [23]. In order to examine the influence of the duration on the parameters, the parameters were calculated every ten minutes under different rainfall intensities. Firstly, Ia was defined as the cumulative rainfall from the beginning of the rainfall to the beginning of runoff, rainfall $P$ was defined as the cumulative 
rainfall from the beginning of the rainfall to the interval time, runoff $Q$ was defined as the cumulative runoff from the beginning of the runoff to the corresponding interval time.

(1). General model fitting

The object was finding $\lambda$ and $S$ of Equation (5) using iterative least squares procedure fitting, which made:

$$
\sum\left\{Q-\left[(P-\lambda S)^{2} /(P+(1-\lambda) S)\right]\right\}^{2}
$$

the minimum. For the interval data of rainfall $P$ and runoff $Q$, the parameters meet: $R^{2}>0.5$.

(2). Event analysis

The $S$ was calculated by putting $I a, P$, and $Q$ into the Equation (4), and $\lambda$ equals $I a / S$. The average of these values of the replicates was taken as the parameters required.

(3). Fu et al.'s methods

Fu et al. used this method to obtain the $C N$ values in the Beijing area. The method is based on the standardized procedure in NEH-630. The initial abstraction ratio is regarded as a constant of 0.2 . The $S$ for a rainfall event in a runoff plot is calculated using the equation:

$$
S=5\left[P+2 Q-\left(4 Q^{2}+5 P Q\right)^{\frac{1}{2}}\right]
$$

The calculated $S$ is converted to the corresponding $C N$ value using Equation (6). According to the antecedent precipitation index (API), most AMC in the Beijing area belongs to AMCI (Fu et al.). Therefor the average of these $C N$ values is taken as the runoff plot $C N 1$ value. The AMC in this study belonged to the same condition, and we used this method to obtain $C N 1$ value to evaluate the parameters based on rainfall intensities and duration.

\subsection{Evaluating Statistics}

After determining the parameters using the above methods, the Nash-Sutcliffe efficiency coefficient (NSE), the percentage deviation coefficient (PBIAS), and the ratio of the root mean square error to the standard deviation of measured data (RSR) were used to evaluate the model parameters. The NSE closer to 1 indicates that the predicted values are closer to the measured values, the better the prediction is; when the NSE is equal to 0 , the predicted values are equivalent to the measured average value, and the predicted values less than 0 are less accurate than the measured average value [24]. The PBIAS is used to measure the relative magnitude of the predicted values and the measured values. The positive values indicate that the predicted values are smaller than the measured values, while the negative values indicates that the predicted values are greater than the measured values [25]. RSR is the ratio of the mean square error of the measured values to the predicted values and the mean square error of the measured values itself. This study used the standards recommended by Moriasi et al. [26], which are NSE $>0.50$, PBIAS $\pm 25 \%$ and RSR $\leq 0.70$. These statistics were computed using the following formulas:

$$
\begin{aligned}
\text { NSE } & =1-\frac{\sum_{i=1}^{n}\left(Q_{o b s i}-Q_{c a l i}\right)^{2}}{\sum_{i=1}^{n}\left(Q_{o b s i}-\overline{Q_{o b s}}\right)^{2}} \\
\text { PBIAS } & =\frac{\sum_{i=1}^{n}\left(Q_{o b s i}-Q_{c a l i}\right)}{\sum_{i=1}^{n}\left(Q_{o b s i}\right)} \times 100
\end{aligned}
$$




$$
R S R=\frac{\sqrt{\sum_{i=1}^{n}\left(Q_{o b s i}-Q_{c a l i}\right)^{2}}}{\sqrt{\sum_{i=1}^{n}\left(Q_{o b s i}-\overline{Q_{o b s}}\right)^{2}}}
$$

where $Q_{o b s i}$ is the runoff depth for the $i$ th rainfall event, $\mathrm{mm}$; $Q_{\text {cali }}$ is the runoff depth calculated for the $i$ th rainfall event, $\mathrm{mm}, \overline{Q_{o b s i}}$ is the simulated runoff average depth, $\mathrm{mm}$, and $n$ is repeating time for validation.

\section{Results}

\subsection{The Process of Runoff and the Results of the Model Components}

The runoff processes under different rainfall intensities along the duration of the experiments is shown in Figure 2. As can been seen, the time for runoff generation is shorter when the rainfall intensities are heavier. The runoff rate of heavier rainfall increases more quickly and to a higher level.

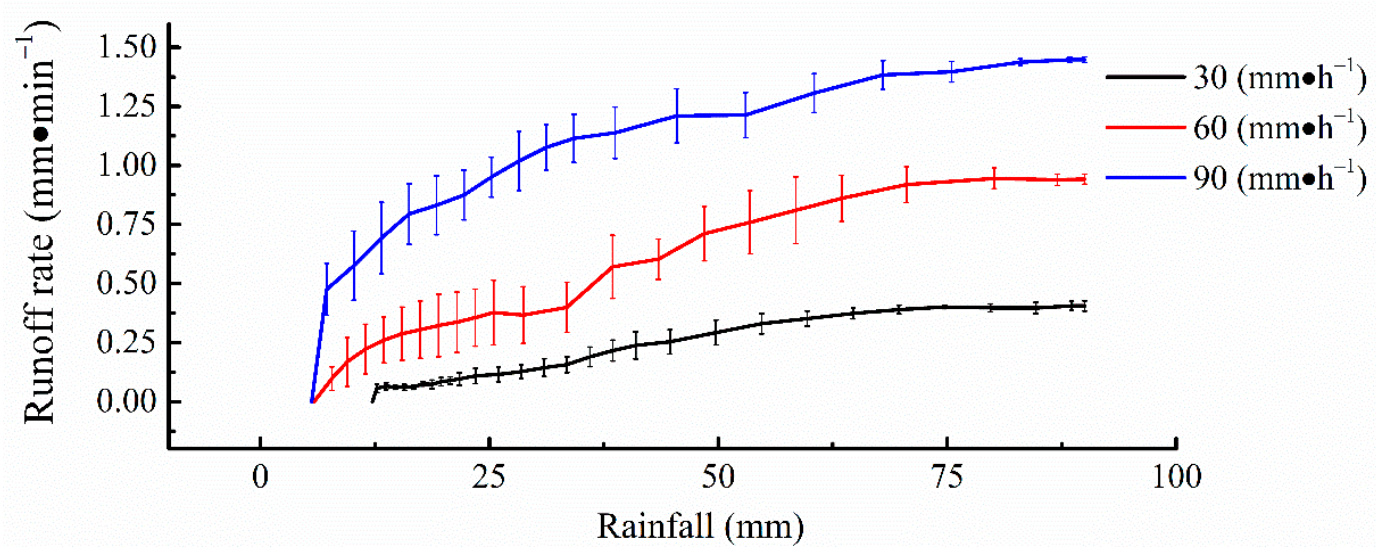

Figure 2. Runoff rate under different rainfall intensities during experiments.

Figure 3 shows $I a$ and total runoff volume for three rainfall intensities. The Ia was calculated by event analysis method. As can been seen the Ia decreased with the increase in rainfall intensity. The total runoff increased with the rainfall intensities, although the rainfall volume was the same. The reason may be that there was short time for the water to infiltrate.

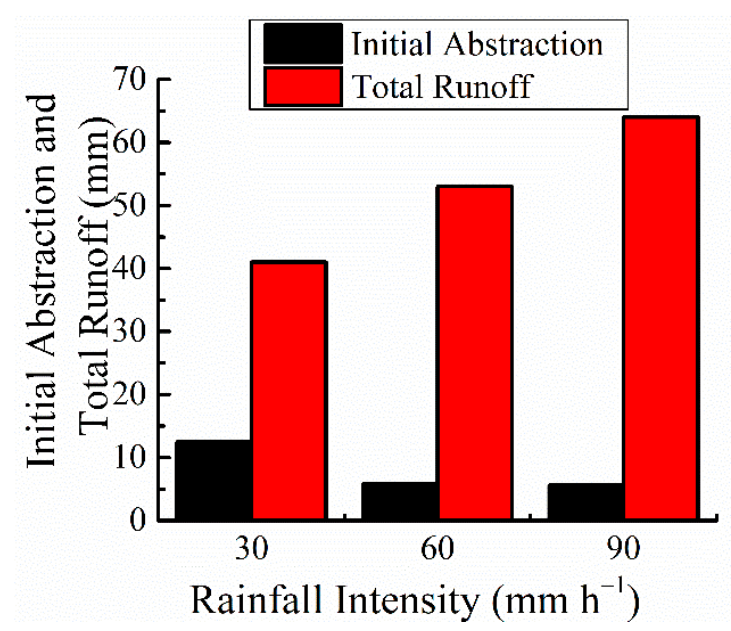

Figure 3. Ia and total runoff volume in experiments. 


\subsection{The Value of the Parameters of SCS-CN}

Figure 4 shows the results of $S$. As can be seen, $S$ increased to the peak then descended, except for $S$ under $90 \mathrm{~mm} / \mathrm{h}$ rainfall intensity condition obtained with the general model fitting method, which descended in all durations. $S$ was smaller when the rainfall intensity was bigger. Characteristics of $S$ under different rainfall intensities conditions are shown in Table 3 . The $S$ under $30 \mathrm{~mm} / \mathrm{h}$ rainfall intensity condition was two times more than $S$ under $90 \mathrm{~mm} / \mathrm{h}$ rainfall intensity condition. $S$ under lighter rainfall intensity conditions had a higher variation.
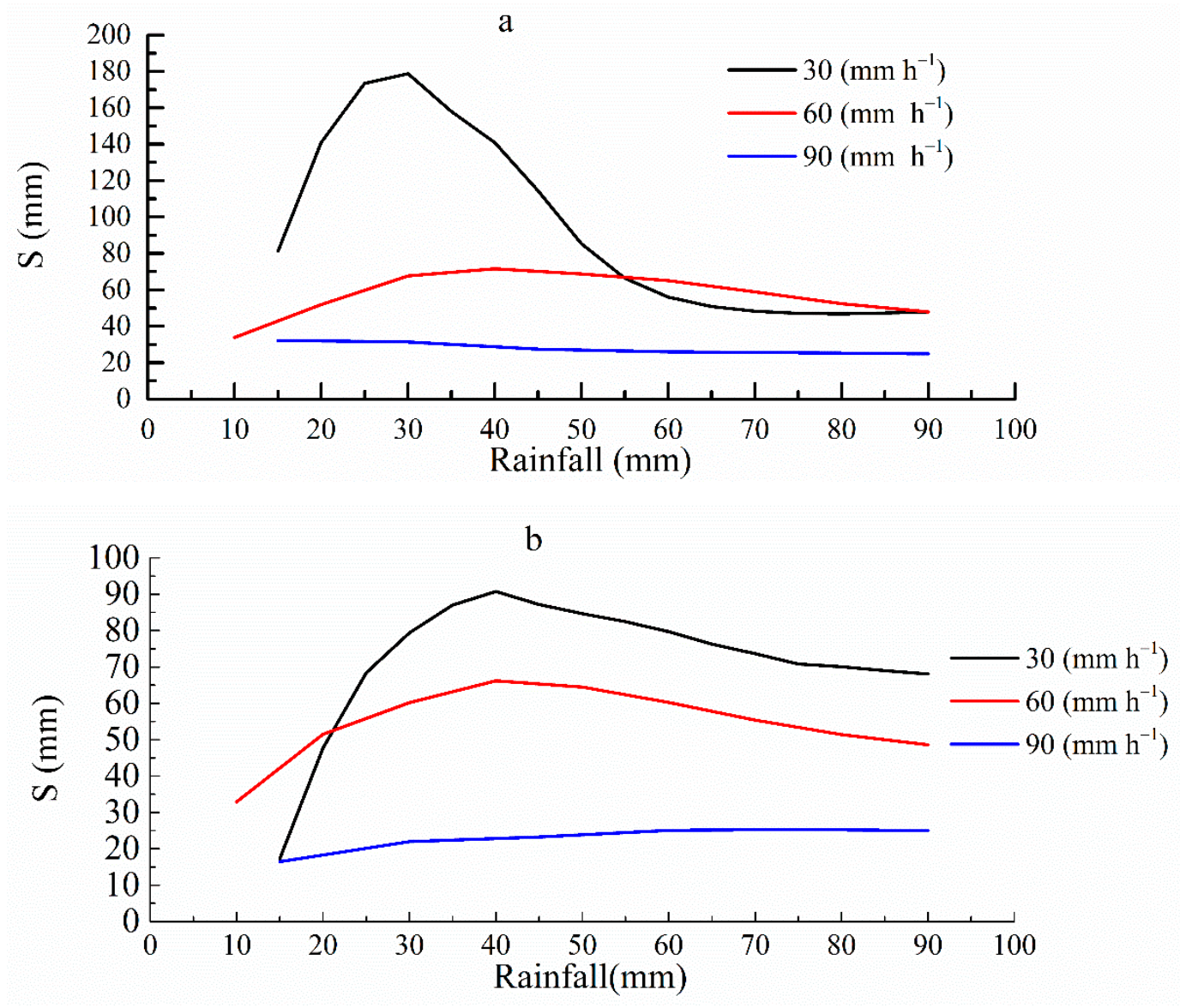

Figure 4. $S$ obtained using: (a) general model fitting, (b) event analysis.

Table 3. Characteristics of $S$ obtained using general model fitting and event analysis.

\begin{tabular}{|c|c|c|c|c|c|c|}
\hline \multirow{3}{*}{ Methods } & \multicolumn{6}{|c|}{ Rainfall Intensity/(mm $\left.\cdot \mathrm{h}^{-1}\right)$} \\
\hline & \multicolumn{2}{|c|}{30} & \multicolumn{2}{|c|}{60} & \multicolumn{2}{|c|}{90} \\
\hline & Mean & STDV & Mean & STDV & Mean & STDV \\
\hline General Model Fitting & 93 & 50 & 58 & 12 & 28 & 3 \\
\hline Event Analysis & 72 & 18 & 55 & 10 & 23 & 3 \\
\hline
\end{tabular}

Figure 5 shows the results of $\lambda$. This parameter decreased at first then increased along the duration, except for the result under $90 \mathrm{~mm} / \mathrm{h}$ rainfall intensity condition obtained using the general model fitting method, which increased along all duration. Under different rainfall intensities conditions $\lambda$ were different (see Table 4). 


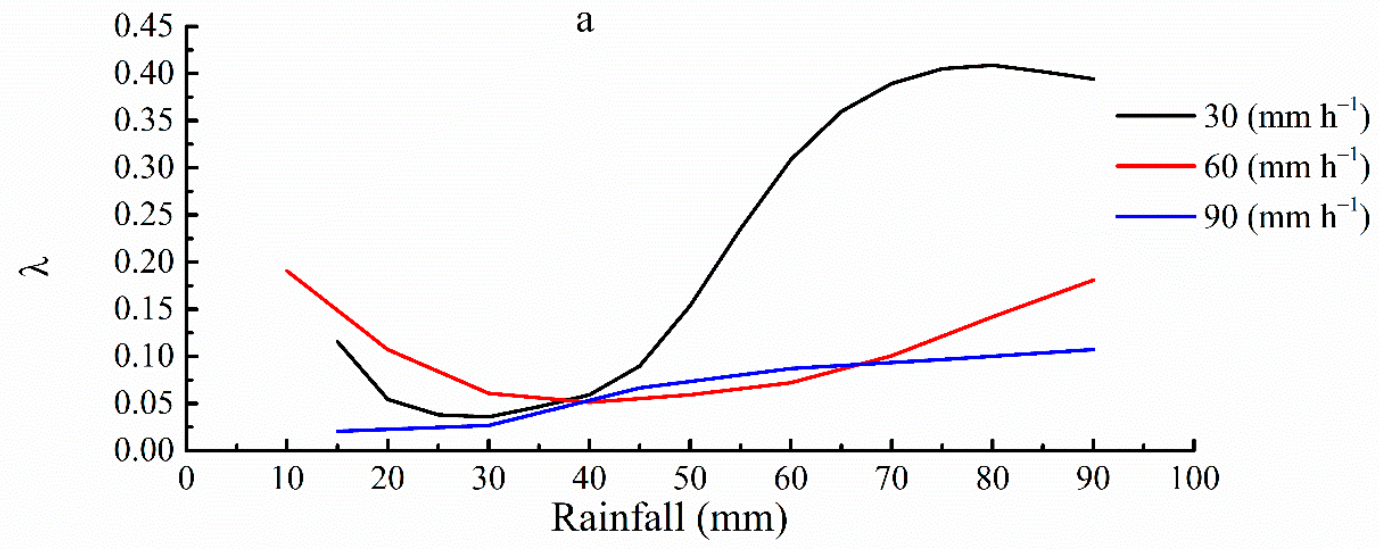

b

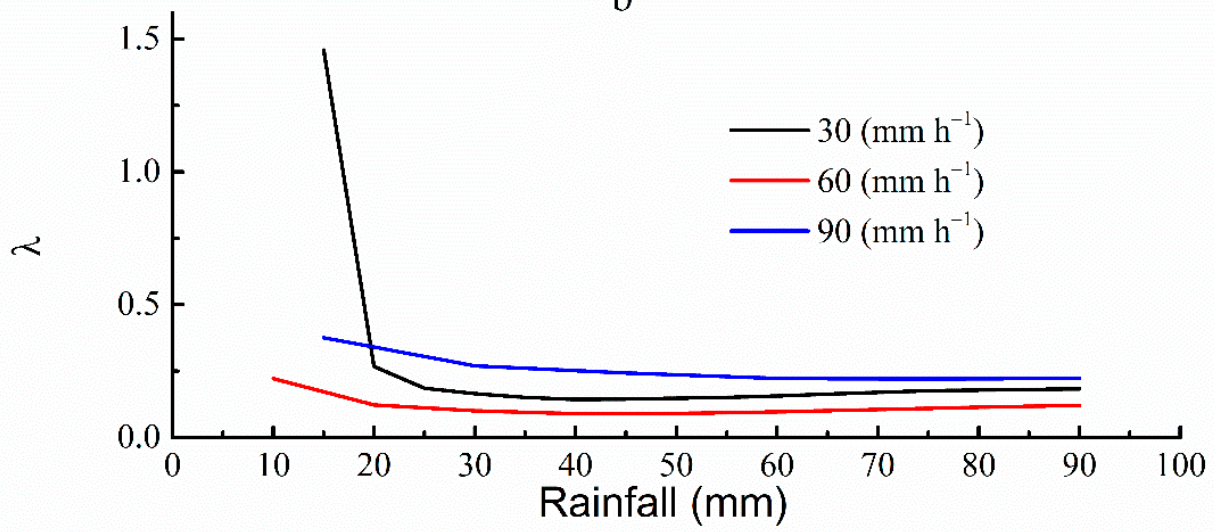

Figure 5. $\lambda$ under different rainfall intensities obtained with: (a) general model fitting, (b) event analysis.

Table 4. Characteristics of $\lambda$ obtained with general model fitting and event analysis methods.

\begin{tabular}{|c|c|c|c|c|c|c|}
\hline \multirow{3}{*}{ Method } & \multicolumn{6}{|c|}{ Rainfall Intensity $/\left(\mathrm{mm} \cdot \mathrm{h}^{-1}\right)$} \\
\hline & \multicolumn{2}{|c|}{30} & \multicolumn{2}{|c|}{60} & \multicolumn{2}{|c|}{90} \\
\hline & Mean & STDV & Mean & STDV & Mean & STDV \\
\hline Genral Model Fitting & 0.22 & 0.16 & 0.11 & 0.05 & 0.07 & 0.04 \\
\hline Event Analysis & 0.25 & 0.32 & 0.12 & 0.04 & 0.26 & 0.06 \\
\hline
\end{tabular}

\subsection{Parameters Choosing and Validation}

The parameters obtained with the two methods were different (Tables 4 and 5). Initial abstraction obtained with the event analysis method is the same as the actual situation. They were more reasonable parameters. Therefore, we chose the results obtained with the event analysis method as our selection (Table 6). We calculated parameter values (Table 7) using Fu et al.'s method which was used to calculate the SCS-CN model parameters in the Beijing area by Fu et al. [6] to evaluate the parameters we chose.

Table 5. Characteristics of $I a$ under different rainfall intensities conditions obtained using event analysis and general model fitting methods.

\begin{tabular}{ccccc}
\hline \multirow{2}{*}{ Rainfall Intensity/(mm/h $\left.\mathbf{- 1}^{\mathbf{1}}\right)$} & \multicolumn{2}{c}{ Event Analysis } & \multicolumn{2}{c}{ General Model Fitting } \\
\cline { 2 - 5 } & Mean/(mm) & STDV/(mm) & Mean/(mm) & STDV/(mm) \\
\hline 30 & 12.50 & 3.79 & 13.46 & 27.73 \\
60 & 5.83 & 1.07 & 5.62 & 2.84 \\
90 & 5.60 & 1.60 & 1.79 & 0.72 \\
\hline
\end{tabular}


Table 6. Selected parameters under different rainfall intensities and duration.

\begin{tabular}{|c|c|c|c|c|c|c|}
\hline \multirow{3}{*}{ Duration/min } & \multicolumn{3}{|c|}{$\lambda$} & \multicolumn{3}{|c|}{$C N$} \\
\hline & \multicolumn{3}{|c|}{ Rainfall Intensity/(mm $\left.\cdot \mathrm{h}^{-1}\right)$} & \multicolumn{3}{|c|}{ Rainfall Intensity/(mm $\left.\cdot \mathrm{h}^{-1}\right)$} \\
\hline & $30 \mathrm{~mm} \cdot \mathrm{h}^{-1}$ & $60 \mathrm{~mm} \cdot \mathrm{h}^{-1}$ & $90 \mathrm{~mm} \cdot \mathrm{h}^{-1}$ & $30 \mathrm{~mm} \cdot \mathrm{h}^{-1}$ & $60 \mathrm{~mm} \cdot \mathrm{h}^{-1}$ & $90 \mathrm{~mm} \cdot \mathrm{h}^{-1}$ \\
\hline 10 & - & 0.22 & 0.38 & - & 88.76 & 93.91 \\
\hline 20 & - & 0.12 & 0.27 & - & 83.33 & 92.05 \\
\hline 30 & 1.46 & 0.10 & 0.24 & 93.64 & 80.99 & 91.61 \\
\hline 40 & 0.27 & 0.09 & 0.22 & 84.19 & 79.42 & 91.02 \\
\hline 50 & 0.19 & 0.09 & 0.22 & 78.78 & 79.77 & 90.92 \\
\hline 60 & 0.17 & 0.10 & 0.22 & 76.18 & 80.83 & 91.06 \\
\hline 70 & 0.15 & 0.11 & & 74.48 & 82.10 & \\
\hline 80 & 0.14 & 0.11 & & 73.68 & 83.18 & \\
\hline 90 & 0.14 & 0.12 & & 74.45 & 83.95 & \\
\hline 100 & 0.15 & & & 75.00 & & \\
\hline 110 & 0.15 & & & 75.49 & & \\
\hline 120 & 0.16 & & & 76.12 & & \\
\hline 130 & 0.16 & & & 76.91 & & \\
\hline 140 & 0.17 & & & 77.52 & & \\
\hline 150 & 0.18 & & & 78.2 & & \\
\hline 160 & 0.18 & & & 78.38 & & \\
\hline 170 & 0.18 & & & 78.64 & & \\
\hline 180 & 0.18 & & & 78.86 & & \\
\hline
\end{tabular}

Table 7. Parameter values obtained with Fu et al.'s method.

\begin{tabular}{cccc}
\hline Soil Type & Antecedent Soil Moisture Condition & $\lambda$ & $C N$ \\
\hline B & AMCI & 0.2 & 81 \\
\hline
\end{tabular}

The results of the three evaluating statistics for the chosen parameters are shown in Table 8. As can be seen, all statistics for the selected parameters were above the suggested value. NSE was above 0.9, PBIAS was in the range of -3.00 to -5.33 , and RSR was less than 0.30 . The statistics for the parameters obtained by Fu et al.'s method declined as the rainfall intensity increased, NSE from 0.95 to 0.67 , PBIAS from -12.65 to 37.80 , and RSR 0.22 to 0.63 . PBAIS was out of the standard range under rainfall intensity of $90 \mathrm{~mm} / \mathrm{h}$. Figure 6 graphically shows the comparison of simulated and measured data. The results predicted by the parameters obtained by event analysis method under different rainfall intensities and duration match the measured results. The results predicted by parameter obtained by Fu et al.'s method deviate 1:1 line more and more as the rainfall intensity increases.

Table 8. Evaluating results, a. for parameters obtained by Fu et al.'s method, b. for parameters obtained with event analysis method under different rainfall intensities and duration.

\begin{tabular}{ccccccc}
\hline \multirow{2}{*}{ Rainfall Intensity/(mm.h $\left.{ }^{-1}\right)$} & \multicolumn{2}{c}{ NSE } & \multicolumn{2}{c}{ PBIAS } & \multicolumn{2}{c}{ RSR } \\
\cline { 2 - 7 } & $\mathbf{a}$ & $\mathbf{b}$ & $\mathbf{a}$ & $\mathbf{b}$ & $\mathbf{a}$ & $\mathbf{b}$ \\
\hline 30 & 0.95 & 0.91 & -12.65 & -3.00 & 0.22 & 0.30 \\
60 & 0.93 & 0.99 & 17.02 & -3.74 & 0.27 & 0.11 \\
90 & 0.67 & 0.97 & 37.80 & -5.33 & 0.63 & 0.19 \\
\hline
\end{tabular}



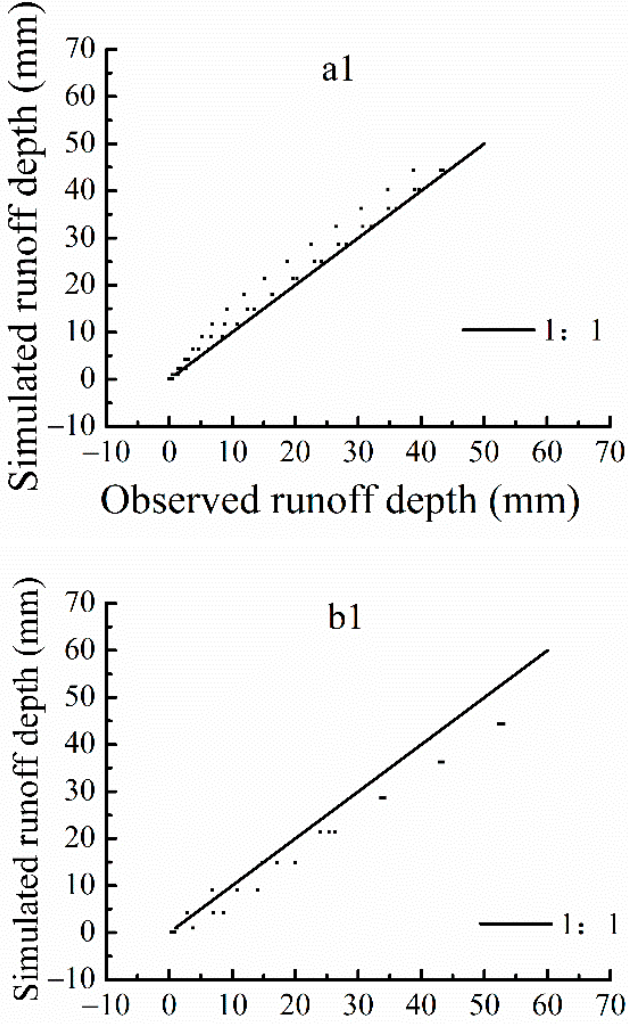

Observed runoff depth $(\mathrm{mm})$

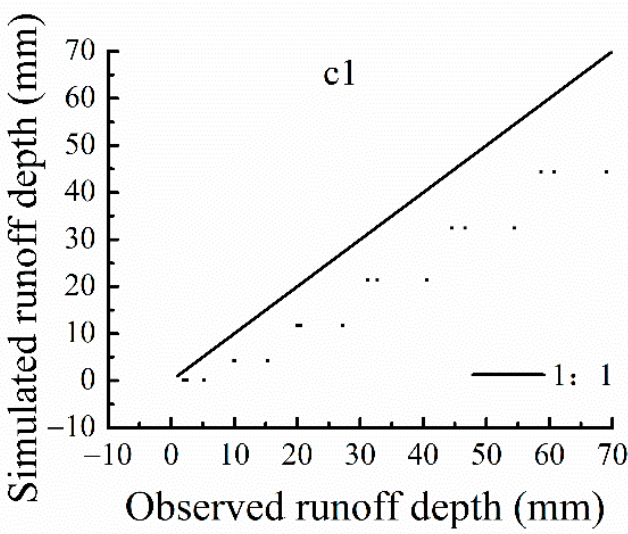

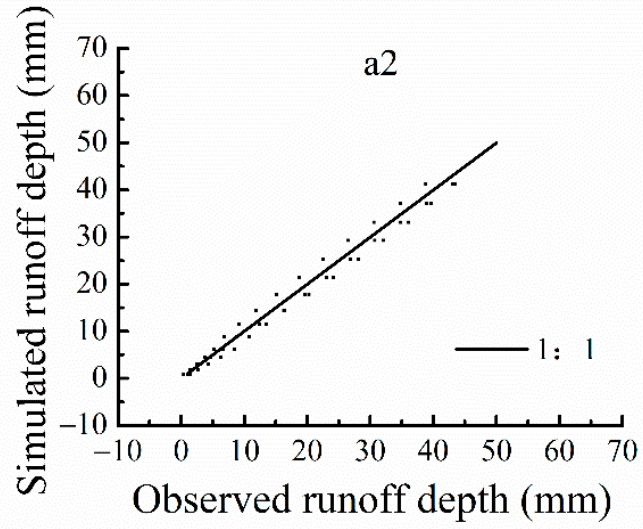
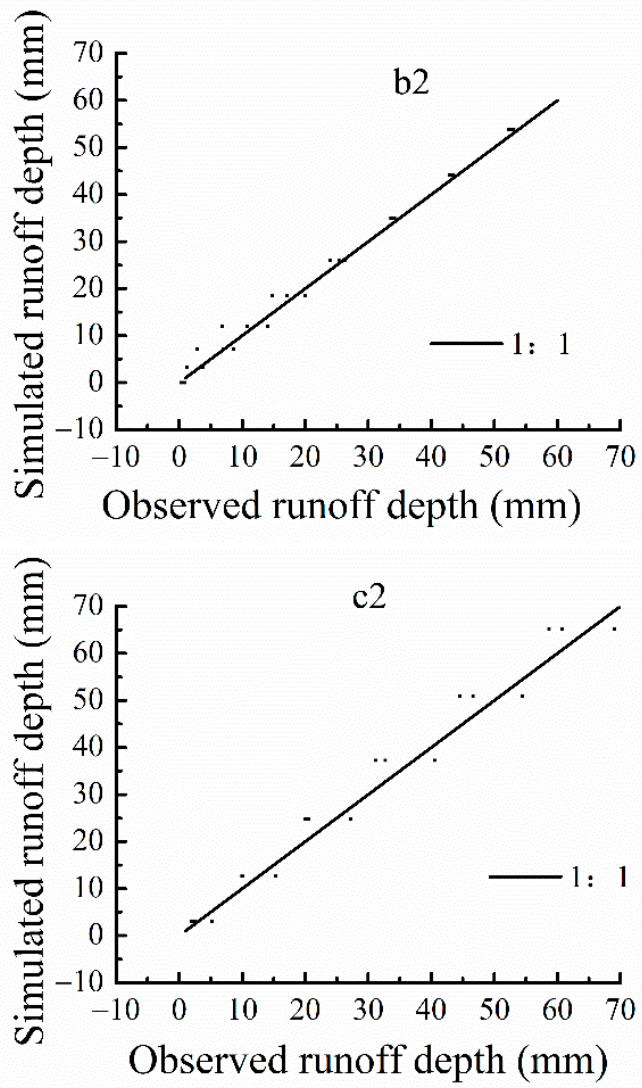

Figure 6. Comparison of measured and simulated runoff, (a1), (b1), (c1) corresponding to parameters obtained by Fu et al.'s method under rainfall intensities 30, 60, 90 mm/h; (a2), (b2), (c2) corresponding to parameters obtained by event analysis method under rainfall intensities 30, 60, $90 \mathrm{~mm} / \mathrm{h}$.

\section{Discussion}

The study in this paper has sought to determine the effects of the rainfall intensities and duration on the parameters of SCS-CN model.

\subsection{The Effect of Rainfall Intensities and Duration on Model's Components}

This simulated rainfall study showed that the beginning time of runoff, total runoff, and initial abstraction changed under different rainfall intensities and duration conditions, although the total rainfall $P$ was identical. These phenomena agree with the previous studies on runoff under different rainfall patterns [21,22]. This is because the hydrological processes are different under different rainfall intensities and duration. The time of flow generation under stronger rain is earlier, and the rainfall process is shorter, so the infiltration is naturally less. These results indicate that the SCS-CN model's 
components change with the rainfall intensities, so it is necessary to study the effect of rainfall intensities and duration on the SCS-CN model parameters.

\subsection{The Effecst of Rainfall Intensities and Duration on $S / C N$ and $\lambda$}

The values of $\mathrm{S}$ obtained by two methods increased first and then decreased along the duration under the same rain intensity. The overall changing trend of $S$ increased with the increase in duration (rainfall depth). Hawkins et al. [27] found that the $C N$ declined as rainfall depth increased in most conditions. This finding is almost the same as the results of this study. In our study, $S$ increased first then decreased in the end. This may be due to small samples, but the change was small when $S$ was transformed into $C N$.

$S$ decreased with the increase in rain intensity. The reason could be that there was littler infiltration as the duration shortened. There was more time for lower intensity rainfall to infiltrate, so the $S$ was bigger. Hjelmfelt [28] deemed $C N$, which is converted from $S$, as a random value, and Banask et al. [29] further pointed out that $C N$ distribution was very important for applying. $S$ decreased with rainfall intensities, which may explain a part of the distribution of $S$. This also can explain that under same rainfall depth, the plant had little effect on runoff reducing under higher rainfall intensity conditions [22].

In our study, $\lambda$ also changed with the rainfall intensities and duration. In the previous literature, it always was seen as a regional constant, which was related to the vegetation, climate, etc. of a region [17]. This study showed that it related to the rainfall intensities and duration. But there was no obvious change trend between different rain intensities. This phenomenon is consistent with previous studies. Some studies concluded that the relationship between $I a$ and $S$ was non-linear [30,31].

Three evaluating statistics (NSE, PBIAS and RSR) of parameters based on rainfall intensities and duration satisfied the standard (Table 8). As the rainfall intensity and duration increased, the deviation from the measured data of prediction by the parameter obtained with Fu et al.'s method increased (Figure 6). The prediction by the parameters based on rainfall intensities and duration were relatively consistent with the measured data under each condition. Pioneer research suggested that $S$ was a random variable [28,32]. Rawls et al. [10] found that the calculation results of the SCS runoff curve were worse than those of the Green-Ampt model which considered the rainfall process. Fu et al. [1] obtained the same conclusion by comparing the slope runoff calculation model in the Beijing area. Sahu et al. [15] combing rainfall intensities into the model, formed modified Sahu-Mishra-Eldho (MSME) model, this MSME's prediction ability improved. But MSME contains new parameters, which makes the application complicated and difficult. In NEH-630 handbook the method of calibration parameter is based on only rainfall and runoff [23]. The result are values for all kinds of rainfall intensities and duration. The influence of rain intensities and duration is not taken into account.

$\mathrm{CN}$ is always used as a transformation of rainfall depth to runoff depth for a given return period [28,33]. The SCS-CN model is sensitive to $C N$ parameters. the change of $C N$ value $\pm 10 \%$ can lead to the change of $55 \%$ to $-45 \%$ of the predicted runoff [34]. In the case of considering the return period, such as the application of the model in hydrological engineering, the model parameters considering the influence of rainfall intensities and duration should be considered, especially when calculating the flood caused by heavy rainfall. The three evaluating statistics indicate that the prediction ability of the SCS-CN method using the parameters calculated by Fu et al.'s method declined as the rainfall intensity increased. Although NSE and RSR were in the suggested range, the PBAIS was out of range under rainfall intensity of $90 \mathrm{~mm} / \mathrm{h}$. The difference between predicted and observed runoff depth increased along the duration. The ranges of difference became larger when the rainfall intensities were heavier. These phenomena indicate that, when using the SCS-CN method to forecast flood for heavy rainfall events, the model parameters should not be selected in the tables in NEH-630 or other tables obtained using the standardized procedure. They should be estimated by the event analysis methods using the rainfall and runoff data from rainfall simulated experiments.

This study was carried out under the same rainfall intensity within the time. In order to acquire the natural condition, the natural rainfall pattern should be studied in the future. 


\section{Conclusions}

Rainfall-runoff synchronization data with different rainfall intensities and durations were obtained by simulated rainfall on runoff plots. The model's components were calculated through these data, and the model parameters were obtained by two methods. Because initial abstraction in the event analysis method is same as the actual, the parameters obtained using the event analysis method was selected. The selected parameters were compared using three statistics with the parameters obtained using Fu et al.'s method, which was based on the standardized procedure in NEH-630. This study indicates that rainfall intensities and duration had effects on the SCS-CN model parameters. The $S$ increased along duration overall but decreased with rainfall intensities, and $\lambda$ changed along the duration and showed no linear relations with rainfall intensities. These dynamic parameters improved model efficiency and accuracy. Rainfall intensity and duration should be considered when this model is used in hydrological designs which consider rainfall intensities and duration, i.e., the return periods.

Author Contributions: Conceptualization, X.W. and H.B.; methodology, H.B.; writing-original draft preparation, X.W.; writing-review and editing, X.W. and H.B.; supervision, H.B.; project administration, H.B.; funding acquisition, H.B. All authors have read and agreed to the published version of the manuscript.

Funding: This research was supported by the National Natural Science Funds of China (No. 31971725), the National Key Research and Development Program of China (No. 2016YFC0501704) and the Beijing Collaborative Innovation Center for Eco-environmental Improvement with Forestry and Fruit Trees (PXM2020_014207_000024).

Acknowledgments: We are grateful to the anonymous reviewers for their constructive comments on the article. We would like to show our deepest gratitude to the editors.

Conflicts of Interest: The authors declare no conflict of interest. The funders had no role in the design of the study; in the collection, analyses, or interpretation of data; in the writing of the manuscript, or in the decision to publish the results.

\section{References}

1. Fu, S.; Liu, B.; Wu, J.; Duan, S. Study on Runoff Calculation Method in Beijing Mountainous Area. Sci. Geogr. Sin. 2002, 22, 604-609. [CrossRef]

2. Perrin, C.; Michel, C.; Andréassian, V. Does a large number of parameters enhance model performance? Comparative assessment of common catchment model structures on 429 catchments. J. Hydrol. 2001, 242, 275-301. [CrossRef]

3. USDA NRCS. Technical Release 55, Urban Hydrology for Small Watersheds, 2nd ed.; United States Department of Agriculture: Washington, DC, USA, 1986; pp. 2-1-2-16.

4. Huang, M.; Gallichand, J.; Dong, C.; Wang, Z.; Shao, M. Use of soil moisture data and curve number method for estimating runoff in the Loess Plateau of China. Hydrol. Process. 2007, 21, 1471-1481. [CrossRef]

5. Chen, Z.; Liu, X.; Zhu, B. Runoff estimation in hillslope cropland of purple soil based on SCS-CN model. Trans. Chin. Soc. Agric. Eng. 2014, 30, 72-81. [CrossRef]

6. Fu, S.; Wang, H.; Wang, X.; Yuan, A.; Lu, B. The runoff curve number of SCS-CN method in Beijing. Geogr. Res. 2013, 32, 797-807.

7. Wang, H. Estimating Watersheds Runoff by Using Improved Runoff Curve Number Model (SCS-CN) on the Loess Plateau of China. Master's Thesis, Beijing Forestry University, Beijing, China, 2016.

8. Zhou, S.; Lei, T. Calibration of SCS-CN Initial Abstraction Ratio of a Typical Small Watershed in the Loess Hilly-Gully Region. Sci. Agric. Sin. 2011, 44, 4240-4247. [CrossRef]

9. Li, S.; Li, Z.; Li, P.; Zhang, T. Study on the influential factors of SCS-CN model parameter S in the Loess Plateau area. Nat. Environ. Pollut. Technol. 2016, 15, 707-713.

10. Rawls, W.J.; Brakensiek, D.L. Comparison Between Green-Ampt and Curve Number Runoff Predictions. Trans. ASAE 1986, 29, 1597-1599. [CrossRef]

11. Huang, M.; Gallichand, J.; Wang, Z.; Goulet, M. A modification to the Soil Conservation Service curve number method for steep slopes in the Loess Plateau of China. Hydrol. Process. 2006, 20, 579-589. [CrossRef]

12. Jiao, P.J.; Xu, D.; Wang, S.L.; Yu, Y.D.; Han, S.J. Improved SCS-CN Method Based on Storage and Depletion of Antecedent Daily Precipitation. Water Resour. Manag. 2015, 29, 4753-4765. [CrossRef] 
13. Rajib, M.A.; Merwade, V. Improving soil moisture accounting and streamflow prediction in SWAT by incorporating a modified time-dependent Curve Number method. Hydrol. Process. 2016, 30, 603-624. [CrossRef]

14. Sahu, R.K.; Mishra, S.K.; Eldho, T.I. An improved AMC-coupled runoff curve number model. Hydrol. Process. 2010, 24, 2834-2839. [CrossRef]

15. Sahu, R.K.; Mishra, S.K.; Eldho, T.I. Improved Storm Duration and Antecedent Moisture Condition Coupled SCS-CN Concept-Based Model. J. Hydrol. Eng. 2012, 17, 1173-1179. [CrossRef]

16. Sahu, R.K.; Mishra, S.K.; Eldho, T.I.; Jain, M.K. An advanced soil moisture accounting procedure for SCS curve number method. Hydrol. Process. 2007, 21, 2872-2881. [CrossRef]

17. USDA-NRCS. National Engineering Handbook, Part 630 Hydrology, Chapter 10 Estimation of Direct Runoff from Storm Rainfall; US Department of Agirculture: Washington, DC, USA, 2004; pp. 10.12-10.19.

18. Li, X. Effect of Tree Crown and Leaf Litter Structures on Related Hydrological and Anti-Erosion Functions of Small Trees on a Process Basis in Beijing Mountainous Area, China; Beijing Forestry University: Beijing, China, 2016.

19. Zhang, Y.G. Numerical Simulation Research on Rainfall Infiltration and Its Application in the Unsaturated Soil; Tianjin University: Tianjin, China, 2014.

20. Beijing Architectural Design Institute Co., Ltd.; General Hospital of Beijing Municipal Engineering Design; Beijing Municipal Water Science and Technology Research Institute. Local Standard of Beijing Municipality Code for Design of Stormwater Management and Harvest Engineering; Beijing Municipal Planning Commission, Beijing Municipal Bureau of Quality and Technical Supervision: Beijing, China, 2014; Volume DB11/685-2013, p. 8.

21. Chang, Y.; Yu, X.X.; Chen, L.H.; Fan, D.X.; Liang, H.R.; Sun, J.M. Effects of undergrowth litter layer on runoff and sediment reduction under simulated rainfall conditions. J. Beijing For. Univ. 2014, 36, 69-74. [CrossRef]

22. Sun, J.M.; Yu, X.X.; Fan, D.X. Effects of Ryegrass on Processes of Soil Infiltration Under Simulated Rainfall. Soils 2014, 46, 1115-1120. [CrossRef]

23. Woodward, D.E.; Hawkins, R.H.; Jiang, R.; Hjelmfelt, J.; Allen, T.; Van Mullem, J.A.; Quan, Q.D. Runoff curve number method: Examination of the initial abstraction ratio. In Proceedings of the World Water \& Environmental Resources Congress 2003, Philadelphia, PA, USA, 23-26 June 2003; pp. 1-10. Available online: https://ascelibrary.org/doi/abs/10.1061/40685(2003)308 (accessed on 14 April 2017).

24. Nash, J.E.; Sutcliffe, J.V. River flow forecasting through conceptual models part i- a discussion of principles. J. Hydrol. 1970, 10, 282-290. [CrossRef]

25. Gupta, H.V.; Sorooshian, S.; Yapo, P.O. Status of Automatic Calibration for Hydrologic Models: Comparison with Multilevel Expert Calibration. J. Hydrol. Eng. 1999, 4, 135-143. [CrossRef]

26. Moriasi, D.N.; Arnold, J.G.; Van Liew, M.W.; Bingner, R.L.; Harmel, R.D.; Veith, T.L. Model evaluation guidelines for systematic quantification of accuracy in watershed simulations. Trans. ASABE 2007, 50, 885-900. [CrossRef]

27. Hawkins, R.H. Asymptotic Determination of Runoff Curve Numbers from Data. J. Irrig. Drain. Eng. 1993, 119, 334-345. [CrossRef]

28. Hjelmfelt, A.T., Jr. Investigation of curve number procedure. J. Hydraul. Eng. 1991, 117, 725-737. [CrossRef]

29. Banasik, K.; Rutkowska, A.; Kohnova, S. Retention and Curve Number Variability in a Small Agricultural Catchment: The Probabilistic Approach. Water 2014, 6, 1118-1133. [CrossRef]

30. Hawkins, R.H.; Khojeini, A.V. Initial abstraction and loss in the curve number method. Hydrol. Water Resour. Ariz. Southwest 2000, 30, 29-35. Available online: https://repository.arizona.edu/handle/10150/296552 (accessed on 17 May 2018).

31. Elhakeem, M.; Papanicolaou, A.N. Estimation of the Runoff Curve Number via Direct Rainfall Simulator Measurements in the State of Iowa, USA. Water Resour. Manag. 2009, 23, 2455-2473. [CrossRef]

32. Hjelmfelt, A.T., Jr.; Kramer, L.A.; Burwell, R.E. Curve numbers as random variables. In Proceedings of the Rainfall-Runoff Relationships, Highlands Ranch, CO, USA, 1982; pp. 365-370.

33. Stewart, D.; Canfield, E.; Hawkins, R. Curve Number Determination Methods and Uncertainty in Hydrologic Soil Groups from Semiarid Watershed Data. J. Hydrol. Eng. 2012, 17, 1180-1187. [CrossRef]

34. Boughton, W.C. A review of the USDA SCS curve number method. Aust. J. Soil Res. 1989, 27, 511. [CrossRef]

(C) 2020 by the authors. Licensee MDPI, Basel, Switzerland. This article is an open access article distributed under the terms and conditions of the Creative Commons Attribution (CC BY) license (http://creativecommons.org/licenses/by/4.0/). 